Article

\title{
Power Spectral Analysis of Heart Rate Variability in Adolescent Male Athletes
}

\author{
Alom M ${ }^{1}$, Begum N², Ferdousi $S^{3}$, Begum $S^{4}$, Ali T ${ }^{5}$
}

\begin{abstract}
Background: Cardiac autonomic nervous activities (CANA) deteriorate with age, obesity, sedentary life style and in various cardiac and noncardiac disease conditions. Regular physical exercise may improve CANA in health and diseases. Power spectral analysis (PSA) of Heart rate variability (HRV) is one of the most promising newer techniques to quantify CANA. Objective: To analyze HRV by Power Spectral method in order to find out the influence of regular physical exercise on CANA in male adolescent athletes. Method: This cross sectional study was carried out on 62 adolescent male athletes aged 12-18 years (group B), in the Department of Physiology, Bangabandhu Sheikh Mujib Medical University from $1^{\text {st July }} 2007$ to $30^{\text {th }}$ June 2008. For comparison, 30 age, sex, BMI and socioeconomic condition matched apparently healthy sedentary subjects (group A) were also studied. The study subjects were selected from the BKSP (Bangladesh Krira Shikka Prothistan, Savar, Dhaka) and the control from a residential school of Dhaka city.Power spectral measures of HRV including Total Power (TP), Very Low Frequency Power (VLF) Low Frequency(LF), High Frequency (HF) LF/HF were measured by a Polygraph . For statistical analysis, Idependent-Sample t-test was used. Results: Total power, HFnu power and the VLF,LF,HF were significantly $(\mathrm{P}<0.001)$ higher and LFnu power and the LF/HF ratio were significantly $(\mathrm{P}<0.001)$ lower in athletes than those of nonathletes which indicate higher cardiac parasympathetic and lower sympathetic activity in athletes. Conclusion: Cardiac Autonomic regulation with increased parasympathetic and decreased sympathetic modulation may occur with in athletes engaged with regular physical exercise.
\end{abstract}

Key words: Power Spectral Analysis (PSA), CANA, Athelet, Adolescent

J Bangladesh Soc Physiol. 2009 Dec;4(2): 26-33

For author affiliations, see end of text.

http//www.banglajol.info/index.php/JBSP

\section{Introduction}

$\Gamma$ The cardiac autonomic nervous activities deteriorate in health and various cardiac and non-cardiac disease conditions.

Regular physical exercise may be a nonpharmacological, easy, safe and economic tool to improve the cardiac autonomic nervous activities in health and diseases ${ }^{1}$. Power spectral analysis (PSA) of Heart rate variability (HRV) is one of the most promising newer techniques to quantify CANA ${ }^{2}$.

In healthy individual, HRV declines with age and also in people with sedentary life style ${ }^{3,4}$. HRV also declines in several cardiac and noncardiac disease conditions like myocardial infarction, heart failure, hypertension, cardio-myopathy , after heart transplant, ventricular arrhythmias, conditions lead to cardiac arrest or sudden death, obesity, diabetes, renal failure and chronically undernourished person ${ }^{5-17}$.

Regular physical exercise improves CANA in healthy individuals ${ }^{3,18-23}$. This kind of improvement of CANA is also observed in Myocardial infarction, coronary artery disease, heart failure, Obesity, type 2 diabetes $^{24-34}$. 


\section{Article}

Though, it was evident that regular physical exercise improves CANA in health and diseases by some studies; yet, a few group of investigators, failed to prove it in healthy individuals ${ }^{35-37}$. On the contrary, some other group of investigators showed that physical exercise does not improve, even in some cases deteriorates CANA in disease conditions ${ }^{38-41}$. Thus, the effect of physical exercise on CANA remains still controversial. In recent days, PSA of HRV to quantify CANA has gained worldwide popularity because it is independent, noninvasive and to some extent detailed informative. The HRV parameters in PSA, as suggested by the Task Force, include Total power, VLF, LF and HF power in absolute value and in normalized unit, and the LF/HF ratio. The total power indicates the total variability of the R-R intervals, the VLF power is supposed to be influenced by thermoregulatory and renin-angiotensin system, LF power by predominantly sympathetic and also parasympathetic, and HF power is strongly associated with vagal tone and represents primary respiratory variation. ${ }^{2}$

In Bangladesh, the number of patients with diabetes, cardiac diseases and renal failure are increasing day by day. Again, a large number of people in our country may be found affected with autonomic nerve dysfunction due to under or over nutrition. In addition, due to rapid urbanization and mechanization of life, sedentary life style may also affect Cardiac Autonomic Nerve Activity in all age groups. Therefore, people should be aware of the adverse effect of sedentary life and also about the benefit of physical exercise as preventive and prognostic measures. Moreover, Power Spectral Analysis of HRV to assess CANA, should also be introduced in our country for research and clinical use, what is already a widely accepted electrophysiologic procedure in many developed countries.

Though, in our country, a few studies were done to assess the CANA in diabetes ${ }^{13}$ and obesity, ${ }^{42}$ by conventional method; but no study was
PSA of Heart Rate Variability in Adolescent Male Athletes

undertaken to document the effect of regular physical exercise on CANA. Moreover PSA of HRV to assess CANA is not yet done in our country .Therefore, this study was carried out to assess the CANA, by PSA of HRV, in healthy adolescent male athletes who perform regular physical exercise and also compare them with healthy adolescent male with sedentary life style in order to evaluate the effect of regular physical exercise on CANA as well as to introduce PSA of HRV in our country for assessing cardiac autonomic nerve function status.

\section{Methods}

This cross-sectional study was carried out in the department of physiology of Bangabandhu Sheikh Mujib Medical University from July 2007 to June 2008. Departmental Ethical Committee approved the protocol. Total number of 92 apparently healthy male adolescents age ranged from 12-18 years were selected, of them 30 nonathletes (sedentary) were taken as control (Group A) and 62 athletes were selected as study group (Group B). Control subjects were selected from a residential school in Dhaka city and the study (Group B) was from Bangladesh Krira Shikkha Prothistan (BKSP), a residential sports academy in Bangladesh. All the control subjects were passing a sedentary life style while the study subjects were exposed to regular physical exercise for at least one year. The subjects were excluded from the study for any subject suffering from systemic diseases, drug users specially drug affecting nervous system and smokers. All ethical considerations for the subjects were taken into account before inclusion in to the study. The aims and benefits of the study were explained to each subject and were encouraged to participate voluntarily. A written informed consent was taken from each subjects and their authority. A detail history regarding physical activity and medical, personal, socio-economic history were taken and thorough clinical examinations of the subjects were done. All these information were recorded in a prefixed questionnaire. Then the subjects

J Bangladesh Soc Physiol. 2009 Dec;4(2): 26-33 
were advised to have his meal by 9:00 p.m., to remain free from any physical and mental stress, not to take any drugs affecting nervous system and to have a good sleep at night before the examination day. The subject was also asked to avoid tea or coffee at breakfast and to attend at the Autonomic Nerve Function Test Laboratory between 9:00 am to 11:00 am on the day of examination. Then after taking detailed history and all physical examinations, the subject was kept under complete bed rest in supine position for 20 minutes in a cool and calm environment at "Autonomic Nerve Function Test Laboratory" of the department of physiology. During this period he was restricted to talk, eat, drink, any physical or mental activity and even sleep. Then all preparations for recording of the HRV parameters was made by connecting the channels for ECG of a Polygraph (RMS INDIA Version2.2). Then a five minutes ECG recording was taken in resting supine position. After recording, all the non-sinus beats were filtered out from the ECG and the frequency domain measures of the HRV i.e. Total power, VLF power, LF power, HF power, LFnu, HFnu and the LF/HF ratio) were obtained from the time series. Measurement of serum glucose and creatinine levels were done in all subjects.All data was recorded systematically in preformed data collection sheet and were expressed as mean \pm SD. Statistical analysis was performed by using SPSS for windows version 12.0. Independent-Sample t-test was performed as applicable.

\section{Results}

The anthropometric parameters of the subjects are presented in Table I. Groups were matched for age and BMI. The mean value of Total power, VLF, LF and HF power was significantly $(\mathrm{P}<0.001)$ higher in group $\mathrm{B}$ than those of group A (Table II).The mean HFnu was significantly $(\mathrm{p}<0.001)$ higher and LFnu \& LF/HF ratio were lower in group B than those of group A. (Table III).All these finding indicate higher parasympathetic and lower sympathetic with sympathovagal balance towards more parasympathetic predominance in athletes.

J Bangladesh Soc Physiol. 2009 Dec;4(2): 26-33
Table I: Mean \pm SD Age, Height, Weight and BMI in two groups $(\mathrm{n}=92)$.

\begin{tabular}{lccc}
\hline Parameters & $\begin{array}{c}\text { Group A } \\
(\mathrm{n}=30)\end{array}$ & $\begin{array}{c}\text { Group B } \\
(\mathrm{n}=62)\end{array}$ & $\begin{array}{c}\text { P } \\
\text { values }\end{array}$ \\
\hline Age(years) & $15.1 \pm 2.54$ & $14.99 \pm 2.23$ & $0.843^{\mathrm{ns}}$ \\
Height(meter) & $1.58 \pm 6.57$ & $1.68 \pm 12.17$ & $0.000^{* * *}$ \\
Weight $(\mathrm{kg})$ & $45.44 \pm 6.77$ & $52.15 \pm 10.36$ & $0.000^{* * *}$ \\
$\mathrm{BMI}\left(\mathrm{kg} / \mathrm{m}^{2}\right)$ & $18.09 \pm 1.72$ & $18.19 \pm 1.61$ & $0.79^{\mathrm{ns}}$ \\
\hline
\end{tabular}

BMI = Body Mass Index.

Group A: Apparently healthy adolescent male nonathletes.

Group B: Apparently healthy adolescent male athletes.

$* * *=\mathrm{P}<0.001$.

$\mathrm{ns}=\mathrm{p}>0.05$.

$\mathrm{n}=$ number of subjects.

Table II: Heart Rate Variability Parameters by Frequency domain method (short term) in absolute value in two groups ( $\mathrm{n}=92)$.

\begin{tabular}{lccc}
\hline Parameters & $\begin{array}{c}\text { Group A } \\
(\mathrm{n}=30)\end{array}$ & $\begin{array}{c}\text { Group B } \\
(\mathrm{n}=62)\end{array}$ & $\begin{array}{c}\text { P } \\
\text { values }\end{array}$ \\
\hline Total power or & $2833.19 \pm$ & $5387.34 \pm$ & $0.000^{* * *}$ \\
Variance $\left(\mathrm{ms}^{2}\right)$ & 282.67 & 850.26 & \\
VLF power & $2456.83 \pm$ & $3117.18 \pm$ & $0.000^{* * *}$ \\
$\left(\mathrm{~ms}^{2}\right)$ & 251.72 & 681.99 & \\
$\mathrm{LF}^{2}$ power & $233.28 \pm$ & $1125.28 \pm$ & $0.000^{* * *}$ \\
$\left(\mathrm{~ms}^{2}\right)$ & 50.35 & 212.84 & \\
$\mathrm{HF}$ power & $139.18 \pm$ & $1123.80 \pm$ & $0.000^{* * *}$ \\
$\left(\mathrm{~ms}^{2}\right)$ & 29.91 & 270.82 & \\
\hline
\end{tabular}

Variance $=$ Total Power, $\mathrm{ms}=$ millisecond, $\mathrm{ms}^{2}=$ squared millisecond.

Group A: Apparently healthy adolescent male nonathletes.

Group B: Apparently healthy adolescent male athletes.

$* * *=\mathrm{P}<0.001$.

$\mathrm{n}=$ number of subjects. 


\section{Article}

Table III: Heart Rate Variability Parameters by Frequency domain method (short term) in two groups ( $\mathrm{n}=92)$.

\begin{tabular}{lccc}
\hline Parameters & $\begin{array}{c}\text { Group A } \\
(\mathrm{n}=30)\end{array}$ & $\begin{array}{c}\text { Group B } \\
(\mathrm{n}=62)\end{array}$ & $\begin{array}{c}\text { P } \\
\text { values }\end{array}$ \\
\hline $\begin{array}{l}\text { LF power } \\
\text { (n.u.) }\end{array}$ & $62.78 \pm 1.81$ & $50.20 \pm 2.21$ & $0.000^{* * *}$ \\
$\begin{array}{l}\text { HF power } \\
\text { (n.u.) }\end{array}$ & $37.29 \pm 1.75$ & $49.81 \pm 2.23$ & $0.000^{* * *}$ \\
$\begin{array}{l}\text { LF/HF } \\
\text { ratio }\end{array}$ & $1.7 \pm 0.14$ & $1.02 \pm .09$ & $0.000^{* * *}$ \\
\hline
\end{tabular}

LF power (n.u.) = Low frequency power in normalized unit, HF power (n.u.) = High frequency power in normalized unit, LF/HF = Ratio of low and high frequency power.

Group A: Apparently healthy adolescent male nonathletes.

Group B: Apparently healthy adolescent male athletes.

$* * *=\mathrm{P}<0.001$.

$\mathrm{n}=$ number of subjects.

\section{Discussion}

The present study analyzed the power spectral components of HRV parameters including the total power, LF power, HF power, VLF power, LFnu, HFnu and LF/HF ratio in adolescent male athletes in order to assess the influence of regular physical exercise on CANA. In this study, all these HRV parameters in both the groups were within normal ranges according to the standard provided by the Task Force. ${ }^{2}$

Significantly higher values of total power ,LF,HF,VLF power were observed in athletes in comparison to non athlete which were similar to the findings reported by other investigators ${ }^{18,22}$, 34,43-48. On the contrary, no such findings were reported by other group of investigators in their studies $3,19,20,37-40$.

Again, significantly lower LFnu and higher HFnu observed in the athletes of the present series are consistent with the findings of most of the investigators in this field $d^{4,15,23,31,33}$ though, some investigators fond no such effects on these. ${ }^{18,36,39,49,50}$
PSA of Heart Rate Variability in Adolescent Male Athletes

.In this study, the LF/HF ratio was significantly lower in athletes in comparison to nonathletes. Similar effects of exercise on sympathovagal balance were reported by most of the investigators of different countries ${ }^{15,19,22-26,31-}$ $33,36,46$ but a few other group of researchers found no suc effects of regular physical exercise on the LF/HF ratio ${ }^{3,18,37}$.

The exact mechanism of exercise-induced changes in CANA is still remains unclear. It has been suggested that physical exercise increases both acetylcholine and choline-acetyl transferase content in cardiac tissue and consequently increases cardiac parasympathetic nervous activity ${ }^{51}$. Billman et al. suggested that physical exercise attenuates cardiac beta-receptor activity and thereby might attenuate the effects of sympathetic activity on heart ${ }^{52}$.

Changes in the total power, LF power, HF power, LFnu, HFnu and LF/HF ratio of the HRV parameters indicate altered CANA. It has been suggested that exercise induced changes in HRV parameters reflect exercise induced changes in CANA $^{3,18,19,23}$. It has also been suggested that the changes in the HF and HFnu components of spectral HRV parameters denote changes in the cardiac parasympathetic activity.Therefore, increased values of these parameters in athletes are suggestive of exercise induced increase in cardiac parasympathetic activity 3,19,49.

Similarly, changes in the LF power and LFnu power are indicative of changes in either the cardiac sympathetic activity or both sympathetic and parasympathetic activity ${ }^{2}$. showing It has been suggested that physical exercise might cause decrease in LFnu power and thereby suggestive of decrease in the cardiac sympathetic activity 23, 33. Higher LF but Lower LF nu in the athletes of the present study though creates controversy on the status of their sympathetic activity but the finding on LFnu which is more representative for sympathetic activity indicate presence of decreased sympathetic activity in the subjects of this series.

J Bangladesh Soc Physiol. 2009 Dec;4(2): 26-33 
Again, the changes in the LF/HF ratio reflects the altered state of the cardiac sympatho-vagal balance. Some groups of investigators suggested that physical exercise could affect the LF/HF ratio,by bringing the changes in the sympathovagal balance ${ }^{19,22,24}$. In the present study, higher HF power and HFnu percentage in the athletes showed higher cardiac parasympathetic activity in them. However, as because the acetylcholine and choline-acetyl transferase activity in the cardiac tissue were not possible to measure in the subjects of his study; so, the exact mechanism of exercise induced increase in cardiac parasympathetic activity cannot be revealed from this type of study. Again, similar to parasympathetic activity the exact mechanism of decrease cardiac sympathetic activity in athletes cannot be elucidated as measurement of the cardiac beta-receptors responsiveness was not possible in this study. Reduced LF/HF ratio in athletes of the present series indicate the state of balance towards parasympathetic predominance which may be due to an effect of increased parasympathetic activity.

\section{Conclusion}

Increased parasympathetic and decreased sympathetic activity with shifting of cardiac sympatho-vagal balance towards more parasympathetic in athlete indicate that regular physical exercise can improve cardiac autonomic nervous activities. and thereby may be beneficial in preventing the occurrence of different cardiac diseases caused by cardiac autonomic neuropathy.

\section{Acknowledgement}

The authors of this article are thankful to the authority of Bangladesh Krira Shikha Prathistan (BKSP) for their cooperation.

\section{Author affiliations}

*1. Md. Mashudul Alom, Assistant professor, Department of Physiology, Sylhet women's Medical College. Sylhet Email: masud_physiol@yahoo.com

J Bangladesh Soc Physiol. 2009 Dec;4(2): 26-33
2. Noorzahan Begum, Professor \& Chairman of the Department of Physiology, Bangabandhu Sheikh Mujib Medical University (BSMMU), Bangladesh. Email: noorzahanbeg@yahoo.com

3. Sultana Ferdousi, Assistant Professor, Department of Physiology, Bangabandhu Sheikh Mujib Medical University (BSMMU), Bangladesh. Email: sferdousiratna@gmail.com

4. Shelina Begum, Professor,Chairman, Department of Physiology, Bangabandhu Sheikh Mujib Medical University (BSMMU), Bangladesh.

5. Taskina Ali, Assistant Professor, Department of Physiology, Bangabandhu Sheikh Mujib Medical University (BSMMU), Bangladesh. Email: taskinadr@gmail.com

\section{Refernces}

1. Bilman GE, Aerobic exercise conditioning: a nonpharmacological antiarrhythmic intervention. J Appl Physiol. 2002; 92: 446-454.

2. Yeragani VK, Sobolewski E, Kay J, Jampala VC, Igel G. Effect of age on long-term heart rate variability. Cardiovasc Res.1997; 35(1): 35-42.

3. Dixon EM, Kamath MV, McCartney N, Fallen L. Neural regulation of heart rate variability in endurance athletes and sedentary controls. Cardiovasc Res. 1992; 26(7): 713 - 9.

4. Janssen MJ, de Bie J, Swenne CA, Oudhof J. Supine and standing sympatho-vagal balance in athletes and controls. Eur J Appl Physiol Occup Physiol.1993; 67 (2): 164-7.

5. Casolo GC, Stroder P, Signorini C, Calzolari F, Zucchini M, Balli E, Sulla A, Lazzerini S. Heart rate variability during the acute phase of myocardial infarction. Circulation. 1992; 85: 2073-2079.

6. Wichterle D, Simek J, La Rovere MT, Schwartz PJ, Camm J, Malik M. Prevalent Low-frequency oscillation of heart rate: Novel predictor of mortality after myocardial infarction. Circulation. 2004; 110:1183-90.

7. La Rovere MT, Pinna GD, Maestri R, Mortara A, Capomolla S, Febo O, FeR-Rari R, Franchini M, Gnemmi M, Opasich C, Riccardi PG, Traversi E, Cobelli F. Short-term heart rate variability strongly predicts sudden cardiac death in chronic heart failure patients. Circulation. 2003; 107:565-570.

8. Guzzetti S, Dassi S, Pecis M. Altered pattern of circadian neural control of heat period in mild hypertension. J Hypertens.1991; 9: 831-838.

9. Counihan PJ, Fer L, Bashir Y, FaR-Rel TG, Haywood GA, McKenna WJ, Assessment of heart 


\section{Article}

rate variability in hypertrophic cardiomyopathy Association with clinical and prognostic features. Circulation. 1993; 88: 1682-1690.

10. Sands KE, Appel ML, Lilly S, Schoen FJ, Mudge $\mathrm{GH}$, Cohen RJ. Power spectra analysis of heart rate variability in human cardiac transplant recipients. Circulation. 1989; 79: 76-82.

11. Huikuri HV, Valkama JO, Airaksinen KEJ. Frequency domain measures of heart rate variability before the onset of nonsustained and sustained ventricular tachycardia in patients with coronary artery diseases.Circulation. 1993; 87: 1220-1228.

12. Huikuri HV, Linnaluoto MK, Seppanen T. Circadian rhythm of heart rate variability in survivors of cardiac arrest. Am J Cardiol.1992; 70: 610-615.

13. Akhter S. Relationship between obesity and autonomic nerve function activity. [Thesis] [Dhaka (Bangladesh)]: BSMMU. 2007.

14. Kudat H, Akkaya V, Sozen AB, Salman S, Demirel S, Ozcan M, Atilgan D, Yilmaz MT, Guven O. Heart rate variability in diabetes patients. $J$ Int Med Res. 2006; 34(3): 291-6.

15. Pagkalos M, Koutlianos N, Kouidi E, Pagakalos E, Mandroukas K, Deligiannis A. Heart rate variability modifications following exercise training in type 2 diabetic patients with definite cardiac autonomic neuropathy. Br J Sports Med. 2008; 42: 47-54.

16. Rahman MM. Assesment of some aspects of autonomic nerve function status in uremic patients with renal failure. [Thesis] [Dhaka (Bangladesh)]: BSMMU. 2005.

17. Mario vaz, Bharati AV, Suchitra S, Nazareth D. Heart rate variability and Baroreflex sensitivity are reduced in chronically undernourished, but otherwise healthy, human subjects. Clin Sci. 2003; 104:295 -302.

18. Costa O, Freitas J, Puig J, Carvalho H, Freitas A, Ramos J, Puga N, Lomba I, Fernandes P, de Freitas F. Spectrum analysis of the variability heart rate in athletes. Rev Port Cardiol. 1991; 10(1): 23-8.

19. Shin K, Minamitani H, Onishi S, Yamazaki H, Lee M. Assessment of training induced adaptation in athletes with spectral analysis of cardiovascular variability signals. Jpn J Physiol. 1995; 45(6):1053 -69 .
PSA of Heart Rate Variability in Adolescent Male Athletes

20. Ishida R, Okada M. Spectral analysis of heart rate variability for the assessment of training effects. Rinsho Byori. 1997; 45 (7): 685-8.

21. Levy WC, Cerqueiria MD, Harp GD, Johannnessen KA, Abrass IB, Schwartz RS, Stratton JR. Effect of endurance exercise training on heart rate variability at rest in healthy young and older men. Am J Cardiol.1998; 82(10):1236-1241.

22. Rennie KL, Hemingway H, Kumari M, Brunner E, Malik M, Marmot M. Effects of moderate and vigorous physical activity on heart rate variability in a British study of civil servant. Am J Epidemiol. 2003; 158: 135 -143.

23. Tulppo MP, Hautala AJ, Makikallio TH, Laukkanen RT, Nissila S, Hughson RL, Huikuri HV. Effects of aerobic training on heart rate dynamics in sedentary subjects. J Appl Physiol. 2003; 95: 364-372.

24. Malfatto G, Facchini M, Bragato R, Branzi G, Sala L, Leonetti G. Short and long-term effects of exercise training on the tonic autonomic modulation of heart rate variability after myocardial infarction. Eur Heart J. 1996; 17: 532 -538.

25. Stahle A, Nordlander R, Bergfeldt L. Aerobic group training improves exercise capacity and heart rate variability in elderly patients with a recent coronary event. A randomized control study. Eur Heart J.1999; 20(22):1638 - 46.

26. Fujimoto S, Uemura S, Tomoda Y, Yamamoto H, Matsukura Y, Horii M, Dohi K. Effects of exercise training on the heart rate variability and QT dispersion of patients with acute myocardial infarction. Jpn Circ J.1999; 63: 577-82.

27. Oya M, Itoh H, Kato K, Tanabe K, Murayama M. Effects of exercise training on the recovery of autonomic nervous system and exercise capacity after acute myocardial infarction. Jpn Circ J.1999; 63(11): 843-8.

28. Iellamo F, Legramante JM, Massaro M, Raimondi G, Galante A. Effects of residential exercise training on baroreflex sensitivity and heart rate variability in patients with coronary heart disease: A randomized controlled study. Circulation. 2000; 102: 2588-92.

29. Takeyama J, Itoh H, Kato M, Koike A, Aoki K, Fu LT, Katagiri T. Effects of physical training on the recovery of autonomic nervous activity during

J Bangladesh Soc Physiol. 2009 Dec;4(2): 26-33 
exercise after coronary artery bypass grafting (CABG). Jpn Circ J. 2000; 64: 809-13.

30. Kiilavouri K, Toivonen L, Naveri H, Leinonen H. Reversal of autonomic derangements by physical training in chronic heart failure by heart rate variability. Eur Heart J. 1995; 16(4): 490-5.

31. Radaelli A, Coats AJ, Leuzzi S, Piepoli M, Meyer TE, Calciati A, Finardi G, Bernardi L, Sleight P. Physical training enhances sympathetic and parasympathetic control of heart rate and peripheral vessel in chronic heart failure. Clin Sci (Lond).1996; 91 Suppl: 92 -4.

32. Malfatto G, Branzi G, Bizzi C, Valli P, Facchini M. Favourable effects of cardiovascular rehabilitation on functional capacity and autonomic balance in elderly patients with heart failure. Monaldi Arch Chest Dis. 2005; 64(2):94-9.

33. Gutin B, Owens S, Slavens G, Riggs S, Treiber F. Effect of physical training on Heart-period variability in obese children. J Pediatr. 1997; 130(6): 938-43.

34. Howorka K, Pumpria J, Haber P, Koller J, Mondrzyk J, Schabmann A. Effects of physical training on heart rate variability in diabetic patients with various degree of cardiovascular neuropathy. Cardiovasc Res. 1997; 34(1): 206-14.

35. Maciel BC, Gallo JL, Martin JA, Lima EC, TeR-Ra FJ, Manco JC. Parasympathetic contribution to bradycardia induced by endurance training in man. Cardiovasc Res. 1985; 19(10): 642-8.

36. Boutcher SH, Stein P. Association between heart rate variability and training response in sedentary middle-aged men. Eur J Appl Physiol Occup Physiol. 1995; 70(1): 75-80.

37. Bonaduce D, Petretta M, Cavallaro V, Apicella C, Ianniciello A, Romano M, Breglio R, Marciano F. Intensive training and cardiac autonomic control in high level athletes. Med Sci Sports Exerc. 1998; 30(5): 691-6.

38. Mazzuero G, Lanfranchi P, Colombo R, Giannuzzi P, Giordano A. Long- term adaptation of 24-h heart rate variability after myocardial infarction. The EAMI Study Group. Exercise Training in Anterior Myocardial Infarction. Chest.1992; 101:304-308.

39. Leitch JW, Newling RP, Basta M, Inder K, Dear K, Fletcher PJ.Randomized trial of a hospital-based

J Bangladesh Soc Physiol. 2009 Dec;4(2): 26-33 exercise training program after acute myocardial infarction: cardiac autonomic effects. J Am Coll Cardiol. 1997; 29(6): 1263-8.

40. Davy KP, Willis WL, Seals DR. influence of exercise training on heart rate variability in postmenopausal women with elevated arterial blood pressure. Clin Physiol. 1997; 17(1): 31-40.

41. Figueroa A, Baynard T, Fernhall B, Carhart R, Kanaley JA. Endurance training improves postexercise cardiac autonomic modulation in obese women with and without type 2 diabetes. Eur J Appl Physiol. 2007; 100(4): 437-444.

42. Alom MK. Autonomic nerve function status in type-2 diabetes, relation to glycaemic status, duration and ionized serum calcium and magnesium concentration. [Thesis] [Dhaka (Bangladesh)]: BSMMU. 2004.

43. Stein PK, Ehsani AA, Domitrovich PP, Kleiger RE, Rottman JN. Effect of exercise training on heart rate variability in healthy older adults. Am Heart $J$. 1999; 138(3): 567-576.

44. Iellamo F, Legramante JM, Pigozzi F, Spataro A, Norbiato G, Lucini D, Pagani M. Conversion from vagal to sympathetic predominance with strenuous training in high performance world class athletes. Circulation. 2002; 105: 2719-2724.

45. Leicht AS, Allen GD, Hoey AJ. Influence of intensive cycling training on heart rate variability during rest and exercise. Can J Appl Physiol. 2003; 28(6): 898-909.

46. Jancik J, Siegelova J, Dobsak P, Svacinova H, Placheta Z, Fiser B, Dusek J, Panovsky R, Spinarova L, Eicher JC. Heart rate variability in patients with heart failure: effects of exercise training. Scripta Medica. 2004; 77 (5-6): 283 - 290.

47. Al-Ani M, Munir SM, White M, Townend J, Coote $\mathrm{JH}$. Changes in R-R variability before and after endurance training measured by power spectral analysis and by the effect of isometric muscle contraction. Eur J Appl Physiol Occup Physiol. 1996; 74(5): 397-403.

48. Schuit AJ, van Amelsvoort LG, Verheij TC, Rijneke RD, Maan AC, Swenne CA, Schouten EG. Exercise training and heart rate variability in older people. Med Sci Sports Exerc. 1999; 31(6): 826-21. 


\section{Article}

49. Buchheit M, Gindre C. Cardiac parasympathetic regulation: respective associations with cardiorespiratory fitness and training load. Am $J$ Physiol Heart Circ Physiol .2006; 291: H451-H458.

50. Raczak G, Pinna GD, La Rovere MT, Maestri R, Danilowicz L, Ratlowski W, Figura M, Szwoch M, Ambroch K. Cardiovagal responses to acute mild exercise in young healthy subjects. Circ J. 2005; 69(8): 976-80.
PSA of Heart Rate Variability in Adolescent Male Athletes

51. DeSchryver C, Mertens J. Heart tissue acetylcholine in chronically exercised rats. Experientia. 1975; 31:316-318

52. Billman GE, Kukielka M, Kelley R, MoustafaBayoumi M, Altschuld RA. Endurance exercise training attenuates cardiac beta-2- adrenoceptor responsiveness and prevent ventricular fibrillation in animal susceptible to sudden death. Am J Physiol Heart Circ Physiol. 2005; 290: H 2590-H2599. 